\title{
Upregulation of homeobox gene is correlated with poor survival outcomes in cervical cancer
}

\author{
Kyung Jin Eoh ${ }^{1}$, Hee Jung Kim ${ }^{1}$, Jung-Yun Lee ${ }^{1}$, Eun Ji Nam ${ }^{1}$, Sunghoon Kim ${ }^{1}$, Sang \\ Wun Kim ${ }^{1}$ and Young Tae Kim ${ }^{1}$ \\ ${ }^{1}$ Institute of Women's Medical Life Science, Department of Obstetrics and Gynecology, Yonsei University College of Medicine, \\ Seoul, Korea \\ Correspondence to: Young Tae Kim, email: ytkchoi@yuhs.ac \\ Keywords: cervical cancer, homeobox genes, survival, TCGA, biomarker \\ Received: July 20, $2017 \quad$ Accepted: August 09, $2017 \quad$ Published: September 16, 2017 \\ Copyright: Eoh et al. This is an open-access article distributed under the terms of the Creative Commons Attribution License 3.0 \\ (CC BY 3.0), which permits unrestricted use, distribution, and reproduction in any medium, provided the original author and source \\ are credited.
}

\section{ABSTRACT}

HOX family members encode transcription factors crucial for embryogenesis and may be associated with carcinogenesis. Here, we evaluated the expression of $39 \mathrm{HOX}$ genes in cervical cancer by using clinicopathological information and gene expression data of $\mathbf{3 0 8}$ patients from The Cancer Genome Atlas (TCGA) database. Correlations between mRNA expression of HOX family members and clinicopathological variables were explored. Seventy-three $(23.7 \%)$ patients died during the follow-up period (median, 22.0 months). Overall mortality was significantly associated with advanced FIGO stage, lymph node metastasis, lymphovascular invasion, and increased HOXA1, HOXA5, HOXA6, and HOXC11 mRNA expression. Kaplan-Meier survival analysis revealed that overall survival was significantly shorter in patients with high HOXA rather than low HOXA expression (HOXA1, $\mathrm{P}=0.012$; HOXA5, $\mathrm{P}=0.008$; and HOXA6, $P=0.006)$. Upregulated HOXA1, HOXA5, and HOXA6 expression are significantly correlated with unfavorable overall survival and increased mortality in cervical cancer patients. Therefore, HOXA expression is a potential cervical cancer prognostic indicator.

\section{INTRODUCTION}

Cervical cancer is a multifactorial disease caused due to genetic, environmental, and epigenetic factors, as well as infection by human papillomavirus [1]. Recently, alterations in the expression of transcription factors have been focused upon for its importance in the development of this malignancy.

A large amount of scientific evidence indicates that the expression levels of many genes involved in normal embryo development are aberrant in and contribute to carcinogenesis [2]. Homeobox (HOX) genes encode homeoproteins, which function as transcription factors in the differentiation and proliferation processes at the time of development of embryonic structures, and their aberrant expression has been found to be associated with carcinogenesis and aggressiveness [3, 4]. HOX genes were first described as factors involved in embryogenesis in the fruit fly, Drosophila melanogaster [5]. HOX genes commonly share a 120-base pair DNA sequence called the homeobox, which codes a 61-amino acid peptide termed as the homeodomain. This domain has been characterized previously using nuclear magnetic resonance spectroscopy $[6,7] . H O X$ genes and their protein structures have also been found in humans $[8,9]$. In the human genome, there are $39 \mathrm{HOX}$ genes located on four different chromosomes, and these genes are the structural and functional homologs of the homeotic complex of Drosophila [10].

Previous studies have reported that upregulation of the $H O X$ gene is related to adverse prognostic factors in cervical cancer, but the majority of these studies have been limited by small sample sizes and have been performed only in vitro. Aberrant expression of $\mathrm{HOXD} 9, \mathrm{HOXC5}$, $H O X C 8$, and HOXB2, HOXB4, HOXC10, and HOXD 13 has been found in cervical cancer cell lines [11-13]. A recent study focused on the mechanism of HPV16 E7mediated epigenetic regulation of $\mathrm{HOX}$ genes showed the master regulatory role of HPV16 E7 in modulating 
the expression of $H O X$ cluster genes [14]. Several studies have also revealed the potential roles of $H O X$ antisense long non-coding RNAs in cervical cancer aggressiveness [15-17]. These results suggest that aberrant expression of $H O X$-related genes is associated with the process of cervical carcinogenesis.

Therefore, in this study, we aimed to analyze the mRNA expression levels of all the 39 HOX genes using data from The Cancer Genome Atlas (TCGA) database [18]. We then went on to explore their correlations with clinical data including survival outcomes in cervical cancer and evaluated the prognostic value of $H O X$ gene expression analysis. To the best of our knowledge, this is the first study to analyze the expression of all $\mathrm{HOX}$ genes using data from the TCGA database. Our findings indicate that measurement of $H O X$ gene expression can help predict prognosis and overall survival in cervical cancer.

\section{RESULTS}

A total of 308 cervical cancer cases were included in this study; of these, 253 were squamous cell carcinoma, 28 adenocarcinomas, 17 mucinous carcinomas, three endometrioid carcinomas, and seven adenosquamous carcinoma cases. The median follow-up period was 22.0 months (range: 0.1-213.6 months). Among the clinicopathological features, overall mortality was found to be associated with FIGO stage III/IV, lymph node metastasis, and lymphovascular invasion (Table 1).

Table 2 shows the correlations between the clinicopathological features and the mRNA expression levels of $H O X$ family genes. When the cases were categorized into low and high mRNA expression groups based on cut-off values determined as medians for each gene, higher HOXA1, HOXA5, HOXA6, and HOXC11 expression was found to be associated with increased overall mortality (odds ratio (OR): 1.858, 95\% confidence interval (CI): 1.086-3.178; OR: 2.003, 95\% CI: $1.167-$ 3.438; OR: 2.162, 95\% CI: 1.256-3.724; and OR: 1.724, 95\% CI: 1.011-2.942, respectively). High FIGO stage also highly correlated with high $H O X B 7$ expression, and lymph node metastasis was found to be associated with high $H O X D 12$ and $H O X D 13$ expression $(\mathrm{P}<0.01)$. Moreover, squamous cell histologic type was found to be highly correlated with high expression of $H O X A 1$, HOXA4, HOXА 7, НOXА9, НОХВ2, НOХВ3, НOXВ5-9, HOXC4, HOXC5, HOXC13, HOXD1, HOXD9, HOXD10, $H O X D 11$, and HOXD13 $(\mathrm{P}<0.001)$.

Linear regression analysis indicated that overall mortality was significantly associated with high mRNA expression levels of HOXA1 $(\mathrm{t}=3.033, \mathrm{P}=0.003)$ (Table 3 ). High expression of the $H O X A 1$ gene was also found to be positively correlated with squamous cell histologic type and lymph node metastasis.

In Kaplan-Meier survival analyses, we found that groups with higher $H O X A 1, H O X A 5$, and $H O X A 6$ mRNA expression levels had significantly unfavorable overall survival than those with a lower level of expression of these genes $(\mathrm{P}=0.012, \mathrm{P}=0.008$, and $\mathrm{P}=0.006$, respectively) (Figure 1).

\section{DISCUSSION}

In this study, we showed that the increased mRNA expression of four HOX genes-HOXA1, HOXA5, $H O X A 6$, and $H O X C 11$ - is independently associated with mortality in cervical cancer based on data from TCGA [18]. Several HOX genes were shown to be correlated with risk factors for poor prognoses including advanced FIGO stage, high grade, lymph node metastasis, and lymphovascular invasion. Interestingly, high expression of most of the $H O X$ genes was found to be strongly associated with squamous cell type histology. In particular, the upregulation of the $H O X A 1, H O X A 5$, and $H O X A 6$ genes were found to be significantly associated with unfavorable overall survival in patients with cervical cancer.

Cancers have been revealed as aberrations in the growth, differentiation, and organization of cell populations [19]. These basic processes are supposed to be tightly coordinated and controlled during embryogenesis as well as in adult tissues [20]. The oncogerminative theory of cancer development suggests that malignant transformation occurs due to the aberrant expression of development-related genes [21]. According to this concept, carcinogenesis is a dynamic self-organizing process that resembles the process of early embryo development. The malignant transformation that arises from gene mutations in combination with epigenetic dysregulation eventually results in reprogramming of somatic cells into immortal cells that simulate germline cells, which is consistent with the characteristics of cancer stem cells or, in other words, oncogerminative cells.

As a developing malignant transformation, the oncogerminative cell is considered to follow the same biological principles as those in play in a germline cell as it develops into a blastocyst-stage embryo [21]. The oncogerminative theory of cancer development hypothesizes that to have a cancer is the same as gestating a damaging embryo. This oncogerminative hypothesis of tumor growth includes five stages of tumor development: (i) malignant transformation of normal cells into oncogerminative cells, i.e. cancer stem cells; (ii) reproduction of the oncogerminative cells; (iii) formation of a multicellular spheroid (a parody of blastocyst formation) characterized by a heterogeneous population of cells in addition to the oncogerminative cells; (iv) vascularization of the oncospheroid and its growth; and (v) development of the majority of malignant tumors together with disaggregation of the oncogerminative cells, their migration into the organism's tissues, and development of metastatic foci of tumor growth [22]. 
Table 1: Correlation between clinicopathological features and overall mortality

\begin{tabular}{|c|c|c|c|}
\hline Variables & Dead, $n=73(\%)$ & Alive, $n=235(\%)$ & P value \\
\hline \multicolumn{4}{|l|}{ Age } \\
\hline$<45$ & $26(35.6)$ & $110(46.8)$ & 0.093 \\
\hline$\geq 45$ & $47(64.4)$ & $125(53.2)$ & \\
\hline \multicolumn{4}{|l|}{ Stage } \\
\hline $\mathrm{I} / \mathrm{II}$ & $48(65.8)$ & $185(81.5)$ & 0.005 \\
\hline III/IV & $25(34.2)$ & $42(18.5)$ & \\
\hline \multicolumn{4}{|l|}{ Histology } \\
\hline Squamous Cell & $62(84.9)$ & $191(81.6)$ & 0.733 \\
\hline Adenocarcinoma & $5(6.8)$ & $23(9.8)$ & \\
\hline Mucinous & $5(6.8)$ & $12(5.1)$ & \\
\hline Endometrioid & 0 & $3(1.3)$ & \\
\hline Adenosquamous & $1(1.4)$ & $5(2.1)$ & \\
\hline \multicolumn{4}{|l|}{ Grade } \\
\hline 1,2 & $40(63.5)$ & $115(54.0)$ & 0.182 \\
\hline 3,4 & $23(36.5)$ & $98(46.0)$ & \\
\hline \multicolumn{4}{|l|}{ ECOG } \\
\hline 0,1 & $39(90.7)$ & $156(95.7)$ & 0.246 \\
\hline 2,3 & $4(9.3)$ & $7(4.3)$ & \\
\hline \multicolumn{4}{|l|}{ LN metastasis } \\
\hline Yes & $19(54.3)$ & $35(27.3)$ & 0.003 \\
\hline No & $16(45.7)$ & $93(72.7)$ & \\
\hline \multicolumn{4}{|l|}{ LVI } \\
\hline Yes & $25(92.6)$ & $58(45.3)$ & $<0.001$ \\
\hline No & $2(7.4)$ & $70(54.7)$ & \\
\hline
\end{tabular}

ECOG, The Eastern Cooperative Oncology Group performance score; LN, lymph node; LVI, lymphovascular invasion.

A considerable body of evidence has proven the crucial role of $H O X$ genes as developmental genes during embryogenesis as well as the critical role of aberrant $H O X$ gene expression in the development of various tumors [2-4]. However, to the best of our knowledge, our study is the first one to be based on TCGA data and reporting the correlation between upregulated $H O X$ gene expression and aggressiveness of cervical carcinoma. Nevertheless, further studies are needed in the future to fully understand the role of $H O X$ genes in cervical cancer.

Our results also indicate that the analysis of $H O X$ gene expression, especially in cytological or surgical specimens, can help identify patients with cervical cancer who are expected to have a poor prognosis. According to the results of the analysis, we can then recommend more aggressive treatments or more frequent follow-ups for such cases with high risk. Furthermore, novel therapeutic agents need to be developed for refractory cervical cancer patients administered standard treatment. Our results highlighting the correlation between $H O X$ gene upregulation and poor survival outcomes indicate that drugs inhibiting $H O X A$ gene expression could have the ability to induce the inhibition of oncogerminative cells and thus help in the treatment of refractory cervical cancer patients. In fact, one previous in vitro study has shown the potential of the use of a homeobox transcription factor inhibitor in this respect [23].

One major limitation of this study is the shortterm follow-up period; the small number of mortalities observed during this period might weaken the clinical applicability of the current findings. A more comprehensive investigation based on regularly updated 
Table 2: Summary of the correlation between clinicopathological features and mRNA expression counts of homeobox $(H O X)$ family genes

\begin{tabular}{|c|c|c|c|c|c|c|c|c|}
\hline & Age $\geq 45$ & Stage III/IV & Squamous cell & $\begin{array}{c}\text { Grade } \\
3 / 4\end{array}$ & $\begin{array}{c}\text { ECOG } \\
2 / 3\end{array}$ & LN metastasis & LVI & Mortality \\
\hline$H O X A 1$ & & & +++ & & & & & + \\
\hline HOXA2 & & & & + & & + & & \\
\hline \multicolumn{9}{|l|}{ HOXA3 } \\
\hline HOXA4 & & & +++ & & & & & \\
\hline$H O X A 5$ & & & ++ & & & & & ++ \\
\hline HOXА & & & & + & & & & ++ \\
\hline$H O X A 7$ & & & +++ & & & & & \\
\hline НОХАЯ & & & +++ & & & & & \\
\hline \multicolumn{9}{|l|}{ HOXA10 } \\
\hline HOXA11 & & & & + & & & & \\
\hline \multicolumn{9}{|l|}{ HOXA13 } \\
\hline HOXB1 & & & & + & & & & \\
\hline$H O X B 2$ & & & +++ & & & & & \\
\hline$H O X B 3$ & & + & +++ & & & & & \\
\hline$H O X B 4$ & & & ++ & & & & & \\
\hline HOXB5 & & & +++ & & & + & & \\
\hline HOXB6 & & & +++ & & + & & & \\
\hline$H O X B 7$ & & ++ & +++ & & & & & \\
\hline$H O X B 8$ & & + & +++ & & & & & \\
\hline HOXB9 & & + & +++ & & & + & & \\
\hline$H O X B 13$ & & & + & & & & & \\
\hline $\mathrm{HOXC4}$ & & & +++ & & & & & \\
\hline $\mathrm{HOXC5}$ & ++ & & +++ & & & & & \\
\hline HOXC6 & ++ & & + & & & & & \\
\hline $\mathrm{HOXC8}$ & ++ & & + & & & & & \\
\hline \multicolumn{9}{|l|}{ HOXC9 } \\
\hline $\mathrm{HOXC10}$ & & & ++ & & & & & \\
\hline $\mathrm{HOXC11}$ & + & & + & & & + & & + \\
\hline \multicolumn{9}{|l|}{$\mathrm{HOXC12}$} \\
\hline $\mathrm{HOXC13}$ & & & +++ & & & & & \\
\hline$H O X D 1$ & & & +++ & & & & & \\
\hline$H O X D 3$ & & & ++ & & & & + & \\
\hline HOXD4 & & & + & & & & & \\
\hline$H O X D 8$ & & & + & & + & & & \\
\hline HOXD9 & & + & +++ & & & + & + & \\
\hline$H O X D 10$ & & & +++ & & & & + & \\
\hline$H O X D 11$ & & & +++ & & & + & & \\
\hline$H O X D 12$ & & & + & & & ++ & & \\
\hline$H O X D 13$ & & & +++ & & & ++ & + & \\
\hline
\end{tabular}

+ , correlation with $\mathrm{P}$ value $<0.05 ;++$, correlation with $\mathrm{P}$ value $<0.01 ;+++$, correlation with $\mathrm{P}$ value $<0.001$; ECOG, The Eastern Cooperative Oncology Group performance score; LN, lymph node; LVI, lymphovascular invasion. 
Table 3: Linear regression analysis between clinicopathological features and mRNA expression count of $H O X A 1$, HOXA5, HOXA6, and HOXC11

\begin{tabular}{|c|c|c|c|c|c|c|c|c|}
\hline & \multicolumn{2}{|c|}{ HOXА1 } & \multicolumn{2}{|c|}{ HOXA5 } & \multicolumn{2}{|c|}{ HOXA6 } & \multicolumn{2}{|c|}{ НОХС11 } \\
\hline & t value & P value & t value & Pvalue & $t$ value & P value & t value & P value \\
\hline $\mathrm{Age} \geq 45$ & -1.379 & 0.172 & 0.081 & 0.936 & -0.822 & 0.413 & 0.477 & 0.635 \\
\hline Stage III/IV & -0.927 & 0.357 & 0.176 & 0.861 & -0.066 & 0.948 & -0.412 & 0.682 \\
\hline Squamous cell & 4.536 & $<0.001$ & 1.718 & 0.09 & -0.138 & 0.891 & -2.94 & 0.004 \\
\hline Grade $3 / 4$ & 1.567 & 0.121 & -0.076 & 0.94 & -0.917 & 0.362 & -1.099 & 0.275 \\
\hline ECOG $2 / 3$ & 0.358 & 0.721 & 1.458 & 0.149 & 1.585 & 0.117 & -0.449 & 0.655 \\
\hline $\mathrm{LN}$ metastasis & 1.907 & 0.06 & -0.233 & 0.816 & 0.931 & 0.355 & 0.675 & 0.501 \\
\hline LVI & -1.403 & 0.165 & -0.828 & 0.41 & -0.12 & 0.905 & 0.137 & 0.891 \\
\hline Mortality & 3.033 & 0.003 & 0.709 & 0.48 & 1.209 & 0.23 & -0.23 & 0.819 \\
\hline
\end{tabular}

ECOG, The Eastern Cooperative Oncology Group performance score; LN, lymph node; LVI, lymphovascular invasion.

(A)

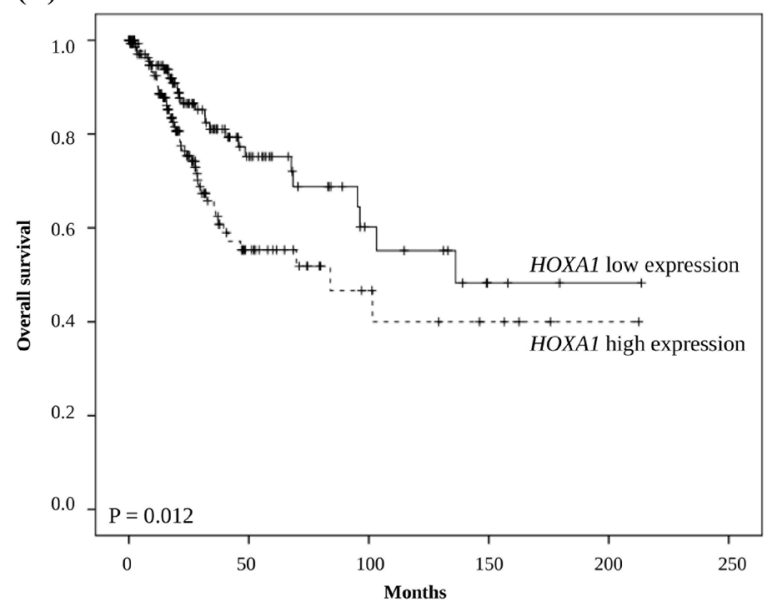

(C)

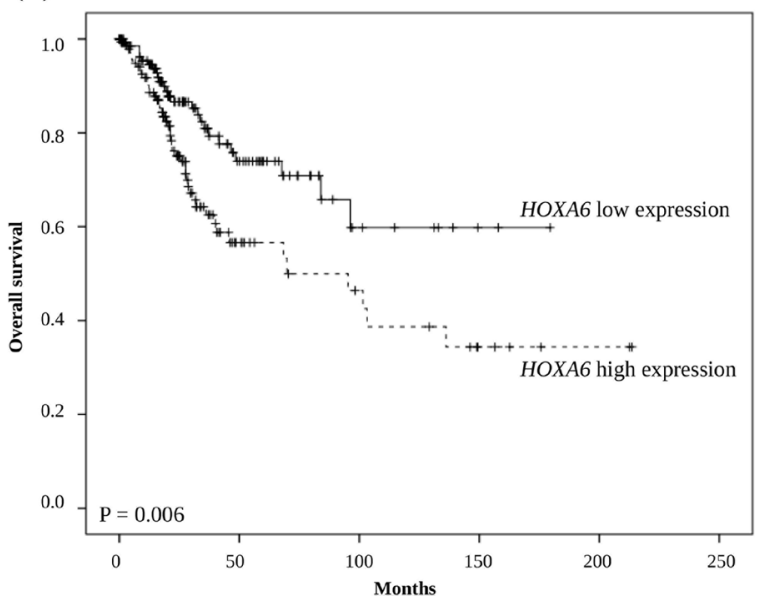

(B)

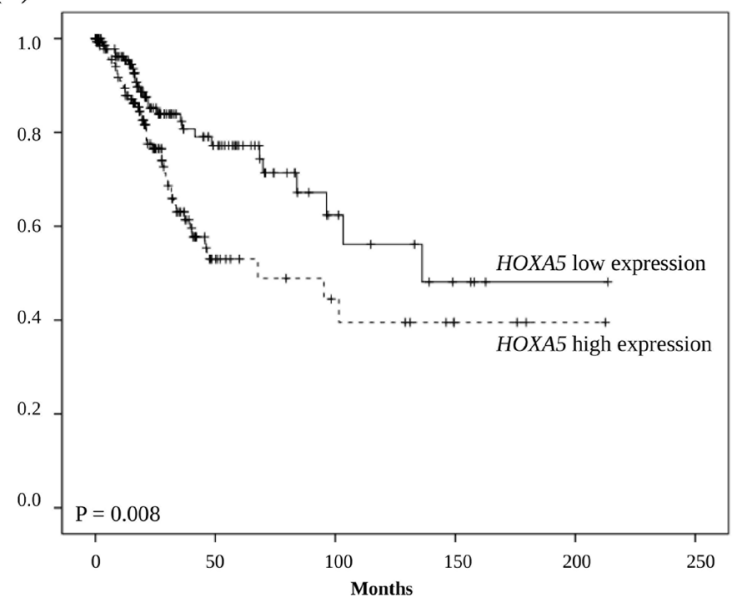

(D)

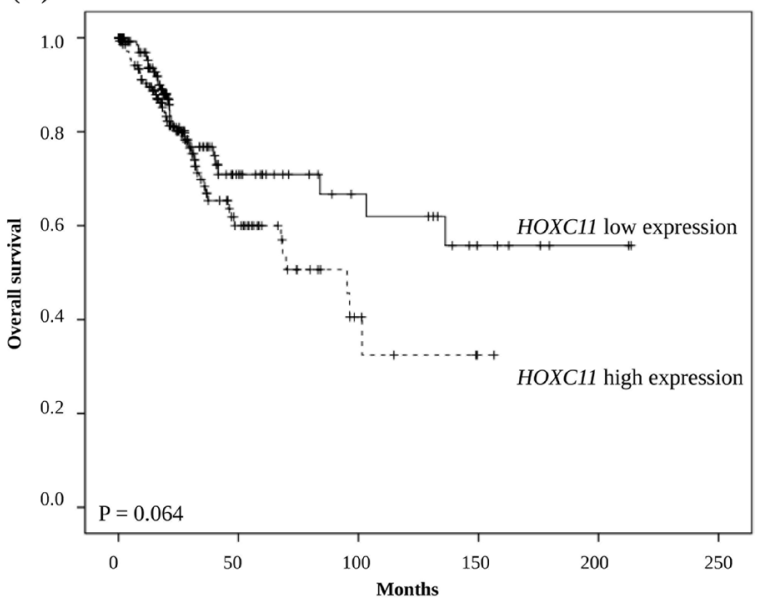

Figure 1: Kaplan-Meier survival analysis of 308 cervical cancer patients stratified by (A) HOXA1, (B) HOXA5, (C) HOXA6, and (D) HOXC11 gene expression levels. 
TCGA data is required in the future. Nevertheless, this study proved the hypothesis that overexpression of $H O X A$ genes is associated with poor prognosis in cervical cancer, based on data obtained using the RNA-seq technique. However, further validation using a different modality such as a microarray or immunohistochemical assay with a large volume might also be needed to verify the results of the present study.

In conclusion, in this study, we showed that the upregulation of the expression of the HOXA1, HOXA5, and HOXA6 genes are significantly associated with unfavorable overall survival as well as increased mortality in a large cohort of cervical cancer cases from TCGA database. Our results indicate that the evaluation of $H O X A$ gene expression may be valuable for predicting prognosis in cervical carcinoma. Also, we could consider $H O X$ gene expression levels may have a potential for use as biomarkers for the same purpose.

\section{MATERIALS AND METHODS}

\section{Data acquisition}

We obtained mRNA expression counts for 39 HOX family genes and the corresponding clinicopathological information from the TCGA data portal (https://tcgadata.nci.nih.gov/tcga/tcgaDownload.jsp). The personal information of the patients is anonymized, and the patients were deidentified. According to TCGA publication guidelines (http://cancergenome.nih.gov/publications/ publicationguidelines), these mRNA sequencing data have no restrictions on publication, and no additional approval by an ethics committee was required to publish the use of the data.

The Illumina Genome Analyzer was utilized as the platform for DNA sequencing (Illumina Inc, San Diego, CA). RNA sequencing data were obtained using Illumina HiSeq 2000 RNA Sequencing Version 2 analysis, and the mRNA expression counts were expressed as RNA-Seq data normalized to data from the pan-cancer database.

\section{Patients}

We collected mRNA expression data for 39 $H O X$ family genes for each patient, along with their clinicopathological features including age at initial pathologic diagnosis, FIGO (The International Federation of Gynecology and Obstetrics) stage, histologic subtype, ECOG (Eastern Cooperative Oncology Group) performance score, lymph node metastasis, lymphovascular invasion, and overall survival (Supplementary Table 1).

\section{Statistical analyses}

We used the Fisher exact or $\chi 2$ tests for categorical variables according to sample size. Linear regression was applied to assess the associations between clinical variables and the expression counts of each $H O X$ gene. We also evaluated $\mathrm{t}$ values for correlation coefficients. Median of $H O X$ gene expression was determined as a cut-off value for the prediction of survival. Kaplan-Meier survival analyses based on calculated cut-off values were performed. SPSS version 23.0 (IBM Corp., Armonk, NY, USA) was used for data analysis.

\section{Author contributions}

Conception \& Design of Study was done by KJE, HJK, JYL, EJN, SK, SWK, and YTK. Data Collection was done by KJE. Data Analysis \& Interpretation was done by KJE and YTK. Statistical Analysis was done by KJE. Manuscript Preparation was done by KJE and YTK. All authors read and approved the final manuscript.

\section{ACKNOWLEDGMENTS}

This work was supported by the Basic Science Research Program through the National Research Foundation of Korea (NRF) funded by the Ministry of Education, Science, and Technology (grant numbers NRF-2015R1A2A2A01008162 and NRF2015R1C1A2A01053516).

\section{CONFLICTS OF INTEREST}

The authors report no conflicts of interest.

\section{GRANT SUPPORT}

None.

\section{REFERENCES}

1. Haverkos HW. Multifactorial etiology of cervical cancer: a hypothesis. MedGenMed. 2005; 7: 57.

2. Abate-Shen C. Deregulated homeobox gene expression in cancer: cause or consequence? Nat Rev Cancer. 2002; 2: 777-85. https://doi.org/10.1038/nrc907.

3. Gehring WJ, Hiromi Y. Homeotic genes and the homeobox. Annu Rev Genet. 1986; 20: 147-73. https://doi.org/10.1146/ annurev.ge.20.120186.001051.

4. Haria D, Naora H. Homeobox gene deregulation: impact on the hallmarks of cancer. Cancer Hallm. 2013; 1: 67-76. https://doi.org/10.1166/ch.2013.1007.

5. Lewis EB. A gene complex controlling segmentation in Drosophila. Nature. 1978; 276: 565-70. https://doi. org/10.1038/276565a0.

6. Billeter M, Qian Y, Otting G, Muller M, Gehring WJ, Wuthrich K. Determination of the three-dimensional structure of the Antennapedia homeodomain from Drosophila in solution by $1 \mathrm{H}$ nuclear magnetic resonance 
spectroscopy. J Mol Biol. 1990; 214: 183-97. https://doi. org/10.2210/pdb1hom/pdb.

7. Qian YQ, Billeter M, Otting G, Muller M, Gehring WJ, Wuthrich K. The structure of the Antennapedia homeodomain determined by NMR spectroscopy in solution: comparison with prokaryotic repressors. Cell. 1989; 59: 573-80. https://doi. org/10.1016/0092-8674(89)90040-8.

8. Nourse J, Mellentin JD, Galili N, Wilkinson J, Stanbridge E, Smith SD, Cleary ML. Chromosomal translocation $\mathrm{t}(1 ; 19)$ results in synthesis of a homeobox fusion mRNA that codes for a potential chimeric transcription factor. Cell. 1990; 60: 535-45. https://doi.org/10.1016/0092-8674(90)90657-Z.

9. Kamps MP, Murre C, Sun XH, Baltimore D. A new homeobox gene contributes the DNA binding domain of the $\mathrm{t}(1 ; 19)$ translocation protein in pre-B ALL. Cell. 1990; 60: 547-55. https://doi.org/10.1016/0092-8674(90)90658-2.

10. Scott MP. Vertebrate homeobox gene nomenclature. Cell. 1992; 71: 551-3. https://doi.org/10.1016/0092-8674(92)90588-4.

11. Hung YC, Ueda M, Terai Y, Kumagai K, Ueki K, Kanda K, Yamaguchi H, Akise D, Ueki M. Homeobox gene expression and mutation in cervical carcinoma cells. Cancer Sci. 2003; 94: 437-41. https://doi.org/10.1111/j.1349-7006.2003. tb01461.x.

12. Alami Y, Castronovo V, Belotti D, Flagiello D, Clausse N. HOXC5 and HOXC8 expression are selectively turned on in human cervical cancer cells compared to normal keratinocytes. Biochem Biophys Res Commun. 1999; 257: 738-45. https://doi.org/10.1006/bbrc.1999.0516.

13. Li H, Huang CJ, Choo KB. Expression of homeobox genes in cervical cancer. Gynecol Oncol. 2002; 84: 216-21. https://doi.org/10.1006/gyno.2001.6498.

14. Saha SS, Chowdhury RR, Mondal NR, Roy S, Sengupta $\mathrm{S}$. Expression signatures of HOX cluster genes in cervical cancer pathogenesis: impact of human papillomavirus type 16 oncoprotein E7. Oncotarget. 2017; 8: 36591-602. https:// doi.org/10.18632/oncotarget.16619.

15. Kim HJ, Eoh KJ, Kim LK, Nam EJ, Yoon SO, Kim KH, Lee JK, Kim SW, Kim YT. The long noncoding RNA HOXA11 antisense induces tumor progression and stemness maintenance in cervical cancer. Oncotarget. 2016; 7: 8300116. https://doi.org/10.18632/oncotarget.12863.
16. Kim HJ, Lee DW, Yim GW, Nam EJ, Kim S, Kim SW, Kim YT. Long non-coding RNA HOTAIR is associated with human cervical cancer progression. Int J Oncol. 2015; 46: 521-30. https://doi.org/10.3892/ijo.2014.2758.

17. Lee M, Kim HJ, Kim SW, Park SA, Chun KH, Cho NH, Song YS, Kim YT. The long non-coding RNA HOTAIR increases tumour growth and invasion in cervical cancer by targeting the Notch pathway. Oncotarget. 2016; 7: 4455871. https://doi.org/10.18632/oncotarget.10065.

18. Cancer Genome Atlas Research Network; Albert Einstein College of Medicine; Analytical Biological Services; Barretos Cancer Hospital; Baylor College of Medicine; Beckman Research Institute of City of Hope; Buck Institute for Research on Aging; Canada's Michael Canada's Michael Smith Genome Sciences Centre; Harvard Medical School; Helen F. Graham Cancer Center \&Research Institute at Christiana Care Health Services; HudsonAlpha Institute for Biotechnology; ILSbio, LLC; Indiana University School of Medicine, et al. Integrated genomic and molecular characterization of cervical cancer. Nature. 2017; 543: 37884. https://doi.org/10.1038/nature21386.

19. Negrini S, Gorgoulis VG, Halazonetis TD. Genomic instability--an evolving hallmark of cancer. Nat Rev Mol Cell Biol. 2010; 11: 220-8. https://doi.org/10.1038/ nrm2858.

20. Vinnitsky VB. Oncogerminative hypothesis of tumor formation. Med Hypotheses. 1993; 40: 19-27. https://doi. org/10.1016/0306-9877(93)90191-R

21. Vinnitsky V. The development of a malignant tumor is due to a desperate asexual self-cloning process in which cancer stem cells develop the ability to mimic the genetic program of germline cells. Intrinsically Disord Proteins. 2014; 2: e29997. https://doi.org/10.4161/idp.29997.

22. Schmitt T, Ogris C, Sonnhammer EL. FunCoup 3.0: database of genome-wide functional coupling networks. Nucleic Acids Res. 2014; 42: D380-8. https://doi. org/10.1093/nar/gkt984.

23. Burton LJ, Dougan J, Jones J, Smith BN, Randle D, Henderson V, Odero-Marah VA. Targeting the nuclear cathepsin L CCAAT displacement protein/cut homeobox transcription factor-epithelial mesenchymal transition pathway in prostate and breast cancer cells with the Z-FY-CHO inhibitor. Mol Cell Biol. 2017; 37. https://doi. org/10.1128/mcb.00297-16. 